\title{
The Practical Research on the Convergence of Higher Vocational Education in the Computer Curriculum System
}

\author{
Feng Yang ${ }^{1, a}$, Youquan Chen ${ }^{2, b}$ and Lidan $\operatorname{Fan}^{3, c^{*}}$ \\ ${ }^{1}$ College of Mechanical Engineering Jilin Teachers' Institute of Engineering \& Technology Changchun, \\ China \\ ${ }^{2}$ Department of Mechanical Engineering Changchun Institute of Engineering Technology Changchun, \\ China \\ aYangfeng@163.com, ㅁQuan3168@sina.com, ${ }^{\mathrm{c}}$ Fanlidan111@163.com
}

Keywords: Curriculum system; Cohesion; Research

\begin{abstract}
The computer professional, for example, the theories and principles of computer professional curriculum system of Higher Vocational Education of cohesion were simply explained, and mainly from three aspects: curriculum goal, curriculum content and curriculum structure of computer professional curriculum system of Higher Vocational Education cohesion tentative research.
\end{abstract}

\section{Introduction}

The Department of education of Guangdong Province about carrying out the convergence of vocational professional teaching standards and curriculum standards development work notice "put forward:" vigorously promote the docking of industry development of integrated vocational talents training system construction, clear in higher vocational talent cultivation orientation, development of a number of high title of professional teaching standards and Curriculum standards, promotion of technical and skilled talents cultivation of cohesion, the suitability and. "Thus, the reform and development of vocational education has become industry competitiveness is an important way to enhance the computer professional, computer professional students to broaden the channels of employment, promote technical talents to transform to the skilled personnel is the important measure. But the author in the process of research found that currently computer courses in Vocational convergence process, vocational schools and vocational schools fragmented, training objectives is not uniform, overlapping teaching content, teaching system is not consistent, leading to the articulation process appears in a waste of educational resources, teaching objectives are disjointed. The author thinks that it is essential to avoid all kinds of problems in the course of the convergence of higher vocational courses in computer major.

\section{The Basis and Principles of Higher Vocational Education in Computer Courses}

The Connection of the Curriculum System of Higher Vocational Education in Computer Science. System Guidance and Overall Planning. Stone Mimi in the master thesis, the construction of my research on the connection between junior high school specialized course system of higher vocational education put forward: a sound system of vocational education should be from beginner to advanced and reasonable structure, progressive convergence of the complete system, interdependence between the system elements and at all levels, in the system as a whole, fragmented or detachment. Thus, higher vocational education is homologous to the education, is a progressive levels, therefore, curricula should be under the guidance of the system theory of overall planning and should not separated and fragmented.

Levels of Progressive and Effective Convergence. The author thinks that the professional skill training of computer major in secondary vocational school is inclined to the students. The ability of the training, that is simply learn to "do"; higher vocational computer professional skills are focused on knowledge Expand and extend, in the "will do" based on the understanding of "how to do" and "better 
to do". Therefore, the secondary vocational school and higher vocational education is the effective convergence of skill level, and it is the process of training the skill talented person.

Skills Continue to Reflect the Difference. The author believes that in the computer professional curriculum system of Higher Vocational Education of cohesion, teachers should according to students at the two stages of different cognitive characteristics and ability level, in accordance with the rules of construction of knowledge, skills, step by step to converge. Should consider developing their skills on the continuity, but also to manifest the student to study the characteristics of personalized development; we should not only according to the actual requirements of computer ability of the students in the post jobs, also want to consider in higher vocational schools at different levels of teaching target and the development direction, the computer professional vocational curriculum articulation is internal consistency, and in the level of personnel training there is a significant difference.

The Connection Principle of the Curriculum System of Computer Specialty in Higher Vocational Colleges. Principle of Sustainable Development. No matter is what kind of level vocational education, its curriculum goals are application type talents training, help students master and post or job characteristics to adapt to the knowledge and skills. Therefore, computer professional curriculum system in Higher Vocational convergence process, teachers should require the ability to understand the university computer professional development and student internships or jobs on the computer, based on the comprehensive consideration of Higher Vocational Education of different levels of personnel training objectives, so as to formulate a can help the students to realize the sustainable development of the curriculum system and standard. Can be the core, employment oriented, docking industry development, construction of a reasonable and efficient integration of curriculum in Higher Vocational Education system.

Skill Sandard Pinciple. Students to form a certain professional ability, it is necessary to use a specific task, a simple theoretical teaching cannot help students to accumulate practical experience, but also cannot help them develop good professional habits. The computer industry development by leaps and bounds, to update the skills with each passing day. Therefore, it is necessary to according to the characteristics of the actual needs of industry development and vocational different levels of ability to design in higher vocational curriculum articulation, and guide students in the specific task flexibility in the use of theory to guide practice, the accumulation of practical experience and skills.

Principle of Samless Cnnection. Different levels of computer vocational education training objectives should be set up on the understanding of characteristics of professional and student internships or jobs of computer ability based, only and industry in close connection with the training goals can makes practical computer talent. In order to realize the school and enterprise seamless butt. Therefore, in the computer professional vocational curriculum and cohesion, to the specific tasks as the carrier of daily learning of students, to create simulated work environment, let the students through the tasks to complete the process to build different levels of computer theory knowledge and operating skills, and combine teaching to study and contain study in music.

Principle of Resource Saring. Due to the lack of the higher vocational school communication, fragmentation, it in the process of convergence appear courses overlap, skills to repeat the phenomenon, resulting in waste of resources of vocational education, vocational education quality degradation and other serious problems also leads to part of a computer professional vocational graduates enter vocational weariness, leave school, affecting the transformation of technical talents to skilled personnel. Therefore, computer professional vocational course cohesion to effective integration of the two kinds of different levels of schools teaching resources, realize the sharing of resources, for according to in higher vocational talents training goal to develop and design different levels of bridging courses, to help students acquire more basic theoretical knowledge and practical job skills.

\section{The Aim of Higher Vocational Courses in Computer Science}

Training Lvel Aalysis. It can be seen that the vocational education is on different levels through the analysis of the curriculum goal of the computer major. The generalization and orientation of the 
computer personnel training objective is general, but on the level, the computer education in the secondary vocational education is the training of skilled personnel, and the training of vocational computer education is the technical personnel. The author believes that due to the particularity of professional computer operating skills, practical job skills problem solving process, it is difficult to have a clear standard to fully distinguish technical personnel and skilled personnel. For example, regardless of the vocational training of technical talents or vocational training of skilled personnel, regardless of their skill level and professional quality is comprehensive, in the judgment and maintenance on the same computer motherboard from the same problems, it is difficult to explain in the solution to the problem of a process in which problems need technical talents to solve a special, what kind of problems need skilled talents of special help. Therefore, the author believes that the training level of the computer professional is different, the different position skills and other factors determine the computer professional training objectives should not be a single. In the middle and higher vocational schools, according to the different talents training level, the reasonable curriculum system should be designed to help the students to realize the sustainable development of their professional ability.

\section{Content Connection of Higher Vocational Courses in Computer Major}

Post Pactice Rquirement Is the Center of the Cnvergence of Hgher Vcational Curses in Cmputer Science. Dr. Xu Guoqing in "practice oriented vocational education curriculum research" a book mentioned: "technical practical knowledge in knowledge structure in the core part, theory of knowledge service in the technology practice knowledge, technology of practical knowledge plays a interpretation, understanding the role." But at present, the professional education of computer science has always been the core of the curriculum system, which is contrary to the objective and nature of the talent training in vocational colleges. The author thinks that the culture of traditional computer professional vocational education is mainly with the technology of skilled talents, modern computer professional vocational education training is mainly to the quality of technical personnel, therefore, regardless of what level of computer education for vocational education and technical practical knowledge can deserved to be heavy in weight. But this does not mean that technology theory knowledge dispensable, but in considering the computer professional training objectives, requirements, the quality of students and other factors, according to the students of technical practical knowledge to understand to select theoretical knowledge, and teach them to use the theoretical knowledge to solve problems encountered in the process of practice knowledge acquisition. Only effectively guide students to explore and understand the operation of theoretical knowledge, to help students really understand the book knowledge and job requirements, in order to build a good technical knowledge framework, in order to adapt to the rapid development of computer industry.

Task Item Is the Form of Higher Vocational Curriculum in Computer Major. The task of the project is to organize the classroom teaching with the help of the specific task, to realize the integrated development of theory and practice teaching mode. Mission designers will be theoretical knowledge in accordance with the learner's cognitive rules and the step by step process is embedded in the specific tasks, learners through the completion of tasks to obtain knowledge and practical experience, achieve mastery of doing and learning and in complete the task in the process of develop good working habits and correct bad career attitudes. The author holds that the computer professional vocational education should create a simulated working environment and specific design tasks, lets the student through the completion of the task to obtain the accumulation of understanding of theory and practice, to realize the knowledge to the migration and extension within the class extracurricular, students post practice and practical work to lay the foundation. In the daily teaching, teachers should according to the characteristics of different levels of computer teaching and personnel training goals and student jobs is closely related to the theoretical system, ensure that students through learning can achieve the positions of professional computer capacity requirements; also fully consider the computer industry development trends and market demand, ensure classroom teaching knowledge and skills to keep pace 
with the times, to help students to construct a more comprehensive and objective knowledge system and the theoretical framework, intermediate technical personnel to the transformation of senior technical talents.

Module Course Teaching Is the Mode of Higher Vocational Course in Computer Major. The author believes that in order to realize the computer professional curriculum of Higher Vocational and technical education of traceless docking, it is necessary to fully consider two different levels of vocational education personnel training objectives and requirements, combined with professional features and requirements of the enterprise development in the major of high vocational computer unified course standard, of professional teaching content optimization and integration, and integration of curriculum content in accordance with the higher vocational talents training target, students learn the actual needs of the cognitive rules and jobs, the module were implemented, the establishment of integrated vocational curriculum. In actual operation, the computer professional course is divided into two modules: basic and special and basic module courses set up specialized computer basic operation skill and theory, to lay the foundation for the students' learning and employment development; a special module is to give full consideration to industry development, job requirements, skill of extension and technology updates, for students to effective integration of "used" and "learn" to lay the foundation.

\section{Structural Cohesion of Higher Vocational Courses in Computer Major}

Reconstruction of "Three Section" Curriculum Structure System. At present, the computer professional vocational education basically is the use of "basic course -- professional theory course -professional practice class" such "three section" course system. The focus of this kind of curriculum system more put in the disciplines of theoretical knowledge and non-professional practice. Therefore, this kind of curriculum system help students construct is mainly according to the theory of knowledge framework, rather than with practical knowledge as the core building. Based on the computer professional talents training target, the author thinks that the computer professional connection between secondary and higher vocational education curriculum design, deal with the traditional teaching of computer curriculum system reconstruction, let students in practical work based on the task completion and reflection to construct the theory framework of knowledge, is the "basic course of professional practice course - professional theory courses" new "three segment type" curriculum system.

Due to a variety of computer practical skills and experience, requires that the student through tasks to complete the process to achieve. Therefore, teachers should be combined with professional characteristics and post computer skills required to design specific tasks and to the task of the working process to achieve computer special course of daily teaching, guide students through the completion of the task of learning process, grasp each specific task completion step, accumulation of each step of the operation experience, to stimulate the students' learning potential, realize the teachers design the teaching objectives. Work structure course not only provides students with the opportunity to practice, but also focus on the completion of the work process of reflection and questioning, so that students take the initiative to solve the problems encountered in the process of completing the work. Due to the students to complete the task of process control, problem solving in the presence of uncertainty. Therefore, teachers must be completed ahead of schedule related tasks involved theories and refining, complete the transformation and unity between tasks and classroom teaching, students Gou Jianzhi knowledge and practice of framework of rationality, continuity and scientific guarantee.

Design Ladder Type Curriculum Connection System. The author believes that to design of computer major in Higher Vocational Curriculum System in full consideration of the secondary and higher vocational colleges by the two different stages of training level, training objectives and competencies based to achieve seamless link of computer practice experience and special skills. Therefore, in higher vocational computer professional curriculum development to fully considered in training level, professional characteristics, job requirements and professional standards are classified, 
the curriculum development process to be in higher vocational computer professional teachers, representatives of industries and enterprises, vocational education experts and professional students participate in the entire process, and construct a reasonable, ladder step by step curriculum system.

\section{Conclusion}

The convergence of higher vocational courses in computer science is a hot topic, and it is also a key direction of the development of computer vocational education. The on the basis of previous studies, combined with his own practice and thinking, put forward some own views, aims to initiate, to attract more professional teachers, industry experts and vocational teach scholars concern about this topic, focus on further development of the vocational education of computer science.

\section{References}

[1] Shi Mimi. Study on the connection of the curriculum system of Higher Vocational Education in China. [J]Qufu Normal University, 2013 (4).

[2] Jiang Dayuan. Rational questions of constructing the system of modern occupation education. [J]Education research, 2011 (11).

[3] Xu Guoqing. Practice oriented vocational education curriculum research. [J]Shanghai Education Publishing House, 2008 (225).

[4] Hu Chongqing. Action oriented approach and its implementation mechanism in vocational colleges.[J] Chinese Vocational and technical education, 2009 (11).

[5] Chen Bingmei. Research on the teaching design of Higher Vocational Education Based on performance technology. [J]Journal of Shenyang Institute of education, 2010 (2).

[6] Research on automatic programming system of plane shaped NC Machining Center for Zhang Jian.SMC3205 stone processing center [D]. Zibo: Shandong University of Technology, 2010

[7] Zhang Xiao. Structure design and Simulation of five axis linkage woodworking CNC engraving machine [D]. Nanjing: Nanjing Forestry University, 2013

[8] ROTH D, S BEDI, F LSMAIL, al. Surface swept by a toroidal cutter during 5 machining [J]. axis Computer Aided Design et, 2001, 33 (1): 35-39.

[9] Bai Liyan, Li Xin, The design of the elevated five axis turning milling center [J]. manufacturing technology and machine tool, 2011 (2):100-103.

[10] Chen Yong. Control system design and implementation of 3D high speed CNC engraving machine based on embedded platform [D]. Chengdu: University of Electronic Science and technology, 2011:1-2. 